Equality and disability symposium

\title{
Disability matters in medical law
}

Kate Diesfeld Auckland University of Technology, Auckland, New Zealand

\begin{abstract}
The British Parliament stated that health services would be covered by the Disability Discrimination Act 1995 (the act). However, when people with disabilities are at their most vulnerable, for example when in hospital or subject to medical procedures, the antidiscrimination law fails them. A review of cases indicates that when people with disabilities are subject to medical treatment, the legislative protections are allowed to vanish. Instead, medical decisions are justified on obscure notions such as "best interests", often with irreversible or even terminal results. This article examines the relevant provisions and limitations of the act, the features of notable non-treatment decisions, and the act's potential to guide future decision making. It argues that antidiscrimination legislation should be assertively applied to protect vulnerable people.

(Fournal of Medical Ethics 2001;27:388-392)
\end{abstract}

Keywords: Disability; learning disability; persistent vegetative state; discrimination; human rights

\section{Introduction}

Generally speaking, it is both immoral and unlawful to discriminate between people on the ground of disability. The gravity and variety of recent cases that involve people who cannot advocate for themselves demands close legal scrutiny. People with disabilities may be medically, socially, and politically vulnerable. Likewise, patients who historically have not been conceptualised as disabled may be protected under the Disability Discrimination Act 1995. The legislation may offer one legal tool for advocates and scholars who have expressed concern regarding controversial medical decisions involving vulnerable people. For purposes of this article, vulnerable people are defined as those who have conditions that have been relevant to the cited cases such as learning disability, cerebral palsy, epilepsy, microcephalia, and persistent vegetative state. On this basis, the implications of the act will be explored.

\section{What is disability?}

The act provides protection for an individual who has a disability (s 1(2)) or has had such a disability (s 2). Four elements must be satisfied for a person to be protected under s.1(1):

a) there must be a physical or mental impairment b) the impairment must adversely affect the individual's ability to carry out normal day-today activities

c) the adverse effect must be substantial

d) the adverse effect must be "long term".

An impairment qualifies if it affects one or more of the following: mobility; manual dexterity; physical coordination; continence; ability to lift, carry or otherwise move everyday objects; speech, hearing or eyesight; memory or ability to concentrate, learn or understand, and perception of the risk of danger. ${ }^{1}$ The legislative intent is to afford protection to people with disabilities in the areas of employment, housing, goods, and services. Inclusion of health services was affirmed during parliamentary debates. ${ }^{2}$

Many people who have been the subject of medical law cases should qualify as disabled under the act, which was intended to protect a wide range of people with disabilities, including those with mental impairments. For example, a person in a persistent vegetative state (PVS) has profound mental and physical impairments that effect her ability to conduct ordinary life activities. Likewise, a person with learning disabilities who is incapable of consenting to or refusing medical procedures should qualify for protection on the ground of mental impairment. People with disabilities who cannot participate in medical decisions are particularly at risk in the medical domain and require the greatest advocacy. ${ }^{34}$ Accordingly, the act's potential should be zealously explored for this most vulnerable group.

It is widely accepted that human beings have worth just because they are human beings and not by virtue of their capacities. ${ }^{56}$ Bodily integrity, sanctity of life, and freedom from coercion are cherished values that apply to all of us, regardless of the type or degree of disability we might have. One would expect the act to include consideration of these core principles, not least since it provides protection where less fundamental matters, such as employment, are concerned. Nevertheless, a number of controversial medical decisions - including tissue extraction, sterilisation, non-treatment, and psychiatric detention-have been made without reference to the act. $^{7}$ However, medical decisions should not be outside the act's remit; they are deserving of scrutiny precisely because they relate to the most fundamental aspects of existence, including its cessation. 
What is discrimination?

The definition of discrimination under the act is problematic because it allows justifications for otherwise discriminatory practices. The act incorporates exceptions into the definition, diluting the protections. It allows direct discrimination, ie the treating of a person less favourably on the basis of disability, if it can be legally justified.

Part III of the act provides a two-prong definition of discrimination. A service provider discriminates if he or she treats a disabled person less favourably for a reason related to the person's disability and which cannot be justified under the act (s20 (1)). Also, a provider discriminates by not providing a disabled person with a reasonable adjustment where required to do so under s 18 and this cannot be justified under the act (s 20(2)). Discrimination is prohibited by:

a) refusing service;

b) treating a person less favourably in the standard of service, or in the manner in which it is provided; or

c) providing the service on less favourable terms. If the provider fails to make reasonable adjustments under s 21, and the effect makes it impossible or unreasonably difficult for a disabled person to make use of a service, this is also unlawful (s 19(1)(b). Five circumstances allow a service provider to justify treatment that would otherwise be discriminatory under s 20(3) and (4); two of the exceptions are particularly relevant for this analysis.

What is the impact of the act's exceptions? A service provider does not discriminate if the treatment is necessary in order to not endanger the health or safety of any person (including the disabled person) under s 20 (4)(a). This exception is problematic because it allows less favourable treatment for the benefit of a third party and its impact is apparent through examination of the case of Y, a 25-year-old woman with a learning disability. ${ }^{9} \mathrm{Y}$ was incapable of consenting to, or refusing, a test and a bone marrow transplant for the benefit of her sister. Clearly, Y received no physical benefit as donor and there was no reported evidence of a close sisterly relationship. The court reasoned, however, that if the ill sister were to die, their mother would be hindered from visiting Y's residential facility due to her bereavement. The court considered the procedures low risk and concluded that it would be in Y's best interests if her sister survived.

One might expect that disability legislation would be relevant to such determinations and yet the court did not cite the act. Would the act have prevented the procedure? Perhaps not. Disability was central to this case; the issue would not have reached the court if $\mathrm{Y}$ had had the legal capacity to consent to, or refuse, the procedures. Yet the $s$ 20 (4) (a) exception allows treatment that is "necessary in order to not endanger the health or safety of any person" [emphasis added]. The act is flawed because it allows interventions for the welfare of any other person to take precedence over the disabled person's interests.
The second exception under s 20 (4)(b) also limits the act's potency. Treatment that is otherwise discriminatory may be justified if the service provider reasonably believes that the disabled person is incapable "of giving an informed consent and for that reason the treatment is reasonable in that case" (emphasis added). This exception is fatuous because it fails to address the complexity of consent issues relating to treatment of people who lack capacity. This approach conflates the issue of consent and discrimination. One's ability to consent should not be the cornerstone for determining whether a procedure is discriminatory. The s $20(4)$ (b) exception can be criticised because it does not assess whether the proposed procedures are unjustifiably invasive and irreversible, have a discriminatory impact, or fail to uphold equal protection principles. Furthermore, the exception distinguishes between people who are capable and incapable of giving consent; the latter are more disabled and arguably should have the greatest protections, precisely on the basis of that vulnerability. ${ }^{10}$

The dangers of this exception are apparent when applied to sterilisation of a woman with a learning disability who lacks the capacity to consent. If she asserts that she is being treated less favourably than non-disabled women in the health service, the service provider may argue that the woman is incapable of providing consent. On this basis, the procedure could be deemed to be reasonable. Again, one would expect that the act would be cited in cases involving highly controversial medical procedures that are administered to people with disabilities. To date, however, the act has not been invoked in this manner and the common law principle of best interests governs sterilisation. ${ }^{11}$

What promise does the act hold in the realm of non-treatment decisions? Perhaps a decision to withhold or withdraw treatment could be challenged on the basis that the health service is unjustifiably refusing service under s 19(2)(a). Although this approach has not been tested, it suggests that the reasoning and impact of recent non-treatment decisions deserve scrutiny.

\section{Is disability relevant to non-treatment decisions?}

The act is intended to eradicate unlawful discrimination against people with disabilities and yet its influence is conspicuously absent in medical jurisprudence. A survey of significant nontreatment decisions demonstrates that disability is fundamental to such decisions but cases that have been decided postenactment have not cited the act. Apparently the stream of non-treatment decisions have flowed unabated by the act or the human rights legislation. Although the act was drafted as the specific vehicle to protect people with disabilities, even in matters less compelling than end-of-life medical decisions, its protections have not been zealously applied.

The following two cases indicate the emergence of the best interest principle for end-of-life 
decisions involving infants with multiple disabilities. J was a five-month-old who had brain damage, profound mental and physical disabilities and was expected to be blind, deaf, and quadriplegic. ${ }^{12}$ Although J was unlikely to develop "even the most basic functions", he was not on the point of death or in the process of dying. $\mathrm{J}$ had required artificial ventilation and doctors asserted that it would be inappropriate to administer it in the event of future collapse. The court weighed the chance of preserving J's life, his quality of life, and the poor prognosis. The best interest principle was central to the court's decision that withholding artificial ventilation would not be unlawful.

This approach was employed in a second case involving an infant named J. ${ }^{13}$ The Court of Appeal considered the withdrawal of artificial ventilation for a 16-month-old with microcephalia, cerebral palsy, epilepsy, and blindness. J required nasogastric feeding and was unlikely to achieve a higher level of functioning. J's life expectancy was uncertain but short. The court was unwilling to require a doctor to treat a patient if, in the clinica judgment of the doctor, such treatment was not in the patient's best interests. To order a doctor to treat against his or her clinical judgment would be an abuse of judicial power. This decision was made over the objection of J's mother.

These cases demonstrate the courts' willingness, for over a decade, to make decisions that shorten the lives of infants with disabilities, based on obscure and conflicting notions of best interests. Surely the mother of J in 1992 believed that she was acting in her child's interest when she opposed the withdrawal decision. The best interests principle gained prominence in PVS cases, beginning with Anthony Bland.

\section{Was Tony Bland disabled?}

A provocative approach to non-treatment decisions is to view the patients through the lens of disability. The following cases involve PVS patients who would now qualify as disabled under section 1 of the act on the basis that they have profound mental and physical impairments which have permanently adverse effects on the patients' ability to carry out any normal activities. The permanent vegetative state was defined in April 1999 by the Royal College of Physicians as a state when "the diagnosis of irreversibility can be established with a high degree of legal certainty. It is a diagnosis which is not absolute but based on probabilities. Nevertheless, it may be reasonably made when a patient has been in a continuing vegetative state following head injury for more than twelve months or following other causes of brain damage for more than six months". ${ }^{14}$

Anthony Bland was in a persistent vegetative state following the tragedy at the Hillsborough stadium in $1989 .{ }^{15}$ His brain functions involving communication, consciousness, and voluntary movement were severely impaired. Three years after the incident, the NHS trust applied for a declaration that withdrawal of artificial hydration and nutrition would not be unlawful. Ultimately, the House of Lords accepted that hydration and nutrition, which it defined as a form of treatment, could be withdrawn on the basis of the patient's best interests. The House of Lords reported that the decision was to be restricted to patients in a persistent vegetative state and not to be a precedent for decisions to withhold or withdraw treatment for patients who had a very low or poor quality of life.

A logical concern is whether the Bland case may lead to the legality of such outcomes for severely disabled people. "The courts have tried to insist that they do not wish to extend sanctioning 'negative treatment' in PVS patients to doing so in other conditions and that they do not engage in assessment of the quality of patients' lives. Yet it would seem that slippage from this moral principle has already begun."

Recently the Family Division reported that the criteria for the diagnosis of PVS produced by the Royal College of Physicians were not fulfilled in two cases. ${ }^{1718}$ Also, by the end of 1998, eighteen PVS cases had been heard and approved by English courts. ${ }^{19}$ The basis of the decisions was the best interests principle. Surely the act was designed to establish and protect the interests of people with disabilities yet it has not featured in these decisions.

Professor Finnis explained that people in a persistent vegetative state are "gravely damaged yet their inability to participate in any other basic human good does not nullify their participation in the good, the benefit, of human life- not even when participation is wounded and as deficient as hopelessly as Bland". ${ }^{20} \mathrm{He}$ argued that acknowledging the humanity of people in a persistent vegetative state does not require that all patients be given all treatment. Rather, he asserted that as citizens of an affluent society, we must strenuously weigh the provision of basic care to people whose death is not imminent when this involves no significant burden; the cessation of care denied "the personhood of these invalids by breaking off human solidarity with them at its roots". ${ }^{21}$

These concerns are equally relevant for people with other debilitating conditions who are at risk of withdrawal of life-sustaining measures. The Bland holding was relevant to later decisions whether to initiate therapeutic measures for people with physical and mental disabilities. $\mathrm{R}$ was born with a brain malformation and cerebral palsy and was described as being in a low awareness state. ${ }^{22}$ At 23 years of age, $\mathrm{R}$ was deteriorating physically and neurologically. A doctor signed a "do not resuscitate order" which the staff of R's day centre challenged through judicial review, asserting it was an irrational and unlawful decision based on the assessment of R's quality of life. The NHS obtained authorisation to withhold cardiopulmonary resuscitation and antibiotics, based on the best interests principle. This case demonstrates the extension of the principle to medical conditions beyond the intent reported by the House of Lords. Future research may demonstrate procedural decay whereby non-treatment decisions are justified for an increasing number of 
conditions, or for less severe, non-chronic, or nonterminal conditions.

\section{Is human rights legislation the answer?}

Recent cases have tested the human rights legislation in end of life decisions involving people with disabilities. D was 19 months old and had multiple disabilities, a lung disease, and short life expectancy. ${ }^{23}$ After his release from hospital, the NHS trust applicants maintained that D's poor state of health and poor prognosis meant it was not in his best interests to undergo artificial and manual ventilation in the future. D's parents argued the application was premature. The court held that the parents' views could not be held to override the court's view of best interests, which was based upon the clinician's assessment. The court examined the cases with regard to the implementation of the European Convention for the Protection of Human Rights and Fundamental Freedoms into domestic law by virtue of the Human Rights Act 1998. It held that there was no breach of articles 2, (right to life) and 3, (the right to not be subjected to inhuman or degrading treatment, including the right to die with dignity). (See schedule 1 to the Human Rights Act 1998.)

A similar human rights analysis in 2000 influenced the fates of Mrs M and Mrs $\mathrm{H}$, two women in persistent vegetative states. ${ }^{24}$ The respective trusts succeeded in obtaining authorisation for withdrawal of nutrition and hydration in the first case to test the right to life protections under article 2 (1) of the Human Rights Act 1998. Dame ButlerSloss reported:

"Although the intention of withdrawing artificial nutrition and hydration in PVS cases is to hasten death, in my judgment the phrase 'deprivation of life' must import a deliberate act, as opposed to an omission, by someone acting on behalf of the state, which results in death ... The death of a patient is the result of the illness or injury from which he suffered and cannot be described as a deprivation., ${ }^{25}$

The High Court held that the analysis of these issues by the House of Lords in Bland was entirely in accordance with the convention case law in article 2 and that it "imposes a positive obligation to give life-sustaining treatment in circumstances where, according to responsible medical opinion, such treatment is in the best interests of the patient but does not impose an absolute obligation to treat if such treatment would be futile".

The definition and implications of futility are themselves notoriously controversial. ${ }^{26}{ }^{27}$ Laurie and Mason assert that the doctor's role has been transformed in relationship to determinations of medical futility. Historically, the doctor made assessments of futility in the face of death, but now must make such assessments of futility in the "face of an unacceptable quality of life". ${ }^{28}$ This marks a significant shift and may in part explain, but not justify, the disturbing events surrounding David Glass's medical treatment.

\section{Disability revisited}

David was 12 years old and had multiple disabilities, including cerebral palsy and epilepsy. His mother wished him to live out his natural life span. ${ }^{29}$ In October 1998, David was in hospital suffering from infections following a tonsillectomy. Clinical staff believed that David was dying and wished to administer diamorphine to alleviate his distress. Over his mother's objection, the diamorphine infusion was administered. Violent incidents between David's family and two doctors led to initiation of civil and criminal proceedings against members of David's family. This medical decision led to violence and demonstrates the controversy that accompanied conflicting perceptions of a disabled boy's best interests.

It is unlikely that the medical staff would have contemplated injecting diamorphine into a child without disabilities, and over the parent's objection. If David had no physical or mental impairment, or it was insubstantial, short term, or didn't hinder his daily activities, he would not have been placed in this precarious position. In short, if David were a non-disabled boy recovering from a tonsillectomy, the medical staff would not have contemplated these measures.

David's medical condition cannot be disentangled from his disability; the act was designed to guard the interests of people with disabilities and the medical procedures involved would qualify as health services. Perhaps David could have asserted that he was discriminated against by the medical staff because there was a failure to provide health service under (s 19(1)(a), or that he was treated less favourably in the standard or manner (s 19(1)(c), or terms (s 19(1)(d) on which the health service was provided. Whether the act in fact would provide protection from the administration of diamorphine is questionable, particularly given the absence of the act's employment in other medical law cases.

\section{Conclusion}

One of the distinct dangers of continued reliance on the Bland best interest principle is the unfettered power it has afforded doctors, who are the gatekeepers to all manner of treatment, including life-sustaining treatment. Professor Finnis exhorts us to consider the "true implications of principles and notions being put into practice by a group of citizens whose medical qualifications, experience, and ethos confer no standing to settle for the whole community such issues of meaning, consistency, humanity, and justice". ${ }^{30}$ The antidiscrimination and human rights legislation offered two potential checks on the medical control over vulnernable individuals.

One might conclude that reliance on the Disability Discrimination Act 1995 or the Human Rights Act 1998 in non-treatment decisions is an inadequate, and ultimately futile, endeavour. Arguably, the shared characteristics of the above patients are also shared by a broad population of legally vulnerable and non-disabled fetuses, neonates, minors, and adults thereby justifying an alternative legal 
approach. For example, the best interest approach has been avoided through enactment of the Adults with Incapacity (Scotland) Act 2000 which allows the appointment of proxy decision makers who are authorised to make medical treatment decisions. ${ }^{31}$ This approach may be a more meaningful strategy than employing legislation that was not explicitly designed for medical decision making. However, any legislation that governs medical decisions for vulnerable patients should incorporate the laudable intent of the antidiscrimination and human rights legislation and include principles of equality, autonomy, justice, and least restrictive alternatives. ${ }^{32}$

What does this state of affairs mean? We are at a juncture where benevolent paternalistic medical decision making intersects with rights-based legislation. Consistently, best interests have been cited as justification for a spectrum of controversial medical decisions. One might legitimately question whether courts have thoroughly assessed alternatives for people who have had their fertility compromised, bodily integrity invaded, liberty restricted, and deaths hastened based on the best interests principle. These controversial procedures are administered to people who qualify as disabled under the act and yet it has not been cited. How are we to negotiate this interface?

\section{Acknowledgments}

I am grateful to Professor David Seedhouse of the National Centre for Health and Social Ethics, Nigel Bryant and Liz Smythe of Auckland University of Technology, and the anonymous assessors for their helpful comments. The views expressed are the author's own.

Kate Diesfeld, BA, Furis Doctorate, is Senior Lecturer and Assistant Director, National Centre for Health and Social Ethics, Faculty of Health Studies, Auckland University of Technology, Auckland, New Zealand.

\section{References and notes}

1 Disability Discrimination Act 1995, schedule 1, para. 4. London: HMSO, 1995.
2 Gooding C. Blackstone's guide to the Disability Discrimination Act 1995. London: Blackstones Press Limited, 1996: 34.

3 Wolfensberger W. The growing threat to the lives of handicapped people in the context of modernistic values. Disability and Society 1994;9:395-413 at 402.

4 Keywood K. Best practice? Health care decision-making by, with and for adults with learning disabilities. Liverpool: University of Liverpool and the Institute of Medicine, Law \& Bioethics, 1999.

5 The Declaration on the Rights of Disabled Persons was proclaimed by the General Assembly of the United Nations on 9 December 1975.

6 Cherry C. Health care, human worth and the limits of the particular. Fournal of Medical Ethics 1997;23:310-14.

7 For analysis of the Disability Discrimination Act 1995 to psychiatric hospitalisation of people with learning disabilities, see Diesfeld K. Neither consenting nor protesting: an ethical analysis of a man with autism. Fournal of Medical Ethics $2000 ; 26 ; 277-81$.

8 See reference $2: 35$.

9 Re Y [1996] 2 FLR 791, (1996) 35 BMLR 111, (1996) 4 Med LR 204.

10 See reference 7: 280

11 Re F (Mental Patient: Sterilisation) [1990] 2 AC 1.

12 Re J [1990] 3 All ER 930, CA.

13 Re J [1992] 4 All ER 614.

14 Royal College of Physicians. The permanent vegetative state. Fournal of the Royal College of Physicians 1996;30:119-21.

15 Airedale NHS Trust v Bland [1993] AC 7891 All ER 821.

16 Laurie GT, Mason JK. Negative treatment of vulnerable patients: euthanasia by any other name? Furidical Review 2000; 13:159-78 at 167

17 Re H (1997) 38 BMLR 11.

18 Re D (1997) 38 BMLR 1.

19 See reference 16: 167 citing British Medical Association. Withholding and withdrawing life-prolonging medical treatment: guidance for decision making. London: BMJ Books, 1999: 54.

20 Finnis JM. Bland: Crossing the Rubicon? The Law Quarterly Review, 1993;109:329-37 at 334.

21 See reference 20:335.

22 Re R [1996] 2 FLR 99, HC.

23 A National Health Services Trust v D The Times 2000 Jul 19.

24 NHS Trust A v Mrs M and NHS Trust B v Mrs H [2000] EWHC 29.

25 NHS Trust A v Mrs M and NHS Trust B v Mrs H [2001] All ER 801, 807

26 Rubin S. When doctors say no: the battleground of medical futility. Bloomington: Indiana University Press, 1998: 25.

27 Mason JK, McCall Smith RA. Law and medical ethics [5th ed]. London: Butterworths, 1999: 26.

28 See reference 16: 166

29 Glass R v Portsmouth Hospitals NHS Trust ex parte Carol [1999] EWCA 1707.

30 See reference 20: 334

31 See reference 16: 172

32 Bingley W. Achieving human rights for people who lack capacity. Fournal of Mental Health Law 2000; Feb:83-90. 